\title{
"Effectiveness of MFCA as a tool to improving sucrose quality in sugarcane production"
}

\begin{tabular}{|c|c|}
\hline AUTHORS & $\begin{array}{l}\text { Mishelle Doorasamy (D https://orcid.org/0000-0001-9320-3461 } \\
\text { Bruce Rhodes }\end{array}$ \\
\hline ARTICLE INFO & $\begin{array}{l}\text { Mishelle Doorasamy and Bruce Rhodes (2017). Effectiveness of MFCA as a tool } \\
\text { to improving sucrose quality in sugarcane production. Environmental Economics, } \\
8(3), 102-110 . \text { doi:10.21511/ee.08(3-1).2017.02 }\end{array}$ \\
\hline DOI & http://dx.doi.org/10.21511/ee.08(3-1).2017.02 \\
\hline RELEASED ON & Wednesday, 11 October 2017 \\
\hline RECEIVED ON & Saturday, 01 July 2017 \\
\hline ACCEPTED ON & Tuesday, 01 August 2017 \\
\hline LICENSE & $\begin{array}{l}(c) \text { EY-Ne } \\
\text { This work is licensed under a Creative Commons Attribution-NonCommercial } 4.0 \\
\text { International License }\end{array}$ \\
\hline JOURNAL & "Environmental Economics" \\
\hline ISSN PRINT & $1998-6041$ \\
\hline ISSN ONLINE & $1998-605 X$ \\
\hline PUBLISHER & LLC "Consulting Publishing Company "Business Perspectives" \\
\hline FOUNDER & LLC "Consulting Publishing Company "Business Perspectives" \\
\hline $0^{0}$ & ニニ: \\
\hline NUMBER OF REFERENCES & NUMBER OF FIGURES \\
\hline 11 & 2 \\
\hline
\end{tabular}

(c) The author(s) 2022. This publication is an open access article. 
Mishelle Doorasamy (South Africa), Bruce Rhodes (South Africa)

\title{
Effectiveness of MFCA as a tool to improving sucrose quality in sugarcane production
}

\begin{abstract}
Sugarcane production in South Africa is one of the major foreign exchange earnings, and constitutes an important contributor to GDP growth of South Africa. It is argued that sucrose content, one of the significant components of sugarcane, has been at the declining trend in the recent years. This study offers Material Flow Cost Accounting (MFCA) as an important tool, since it supports managerial decision making process by making it possible to visualize and quantify material losses. The study hypothesis is that MFCA as tool can increase organizational profitability. The study adopts models from literature to access the efficiency of MFCA as an important alternatives to the conventional accounting process. In this study, production cost has been classified into four categories, namely: system cost, energy cost, material flow cost and residual cost. Accessing the efficiency of this accounting skill, data from South African Sugarcane Milling industry has been adopted to establish our claim in the study and finally, this study has been able to implement the process involved in the use of MFCA. The authors, therefore, recommend the proficient use of MFCA in organizations among the South African industries as it possess the quality of classifying product cost from waste cost and hence improving profitability and organizational efficiency.
\end{abstract}

Keywords: decision making, efficiency, production cost, organizational profitability and material losses.

JEL Classification: 031, Q00

Received on: $1^{\text {st }}$ of July, 2017.

Accepted on: $1^{\text {st }}$ of August, 2017.

\section{Introduction}

The South African sugarcane industry, which contributes close to R8 billion yearly to its economy and approximately R2.5 billion to yearly export earnings, is second only to maize production as a major part of the agricultural sector and is mostly centered in KwaZulu-Natal. It contributes $17.4 \%$ of the total gross value of annual field crop production in South Africa. Furthermore, the sugarcane industry provides 270,000 indirect job opportunities, in addition to the 79,000 jobs directly related to sugarcane production. In fact, it is estimated to provide sustainable livelihoods to a total of about 1 million individuals (Forestry and Fishery, 2011).

The South African sugar industry produces an approximate 2.3 million tons of sugar annually (Anon, 2014a), $75 \%$ of which is marketed and sold within the Southern African Customs Union (SACU), and the remaining $25 \%$ in other parts of Africa, the USA, and Asia. It has thus continued to rank among the top fifteen sugar producing countries in the world.

(C) Mishelle Doorasamy, Bruce Rhodes, 2017.

Mishelle Doorasamy, Lecturer, Department of Accounting, School of Accounting, Economics and Finance, University of Kwa-Zulu Natal, Westville Campus, South Africa.

Bruce Rhodes, Ph.D., Department of Economics, School of Accounting, Economic and Finance, University of KwaZulu-Natal, Westville Campus, Durban, South Africa.

This is an Open Access article, distributed under the terms of the Creative Commons Attribution-NonCommercial 4.0 International license, which permits re-use, distribution, and reproduction, provided the materials aren't used for commercial purposes and the original work is properly cited.
However, a consistent decline in production has been observed over the past two decades peaking in the recent past planting season, with various factors speculated as being responsible. Some of those factors are weakening yields and a reduction in sugarcane production area, according to the Bureau for Food and Agricultural Policy (BFAP) in Anon (2014b); rising input costs and a lack of cohesion and economies of scale (Anon, 2014b; Stainbank, 2011); a growing culture of minimum reinvestment into farm infrastructure (especially among commercial farmers) due to the threat of land claims, poor soil health, and replanting (Anon, 2014b; Harris, 2016).

In addition to the general decline in sugarcane production due to the factors discussed, its international cost competitiveness has been on the rise. Unfavorable weather conditions experienced over the past decade have led to a significant increase in energy-associated input costs, with the situation being aggravated by the falling international sugar prices. These led to a reduction in sugarcane processing, leading to unutilized processing capacity and leaving non-sugars in unprocessed forms.

The quality of sugarcane juice is indicated by the ratio of sugars to non-sugars contained in it, where the higher the amount of sugar, the better for the sugarcane miller. The lower the amount of cane and level of impurities for each ton of caneit has to crush, the easier it is for it to crystallize sugar from the juice. The most important factors contributing to high recovery of sugar are: high sucrose, high purity, low fibre, low level of non-sugars. The level and nature of non-sugars is of great importance, as it has direct impact on the cost of sugar processing and refinement. 


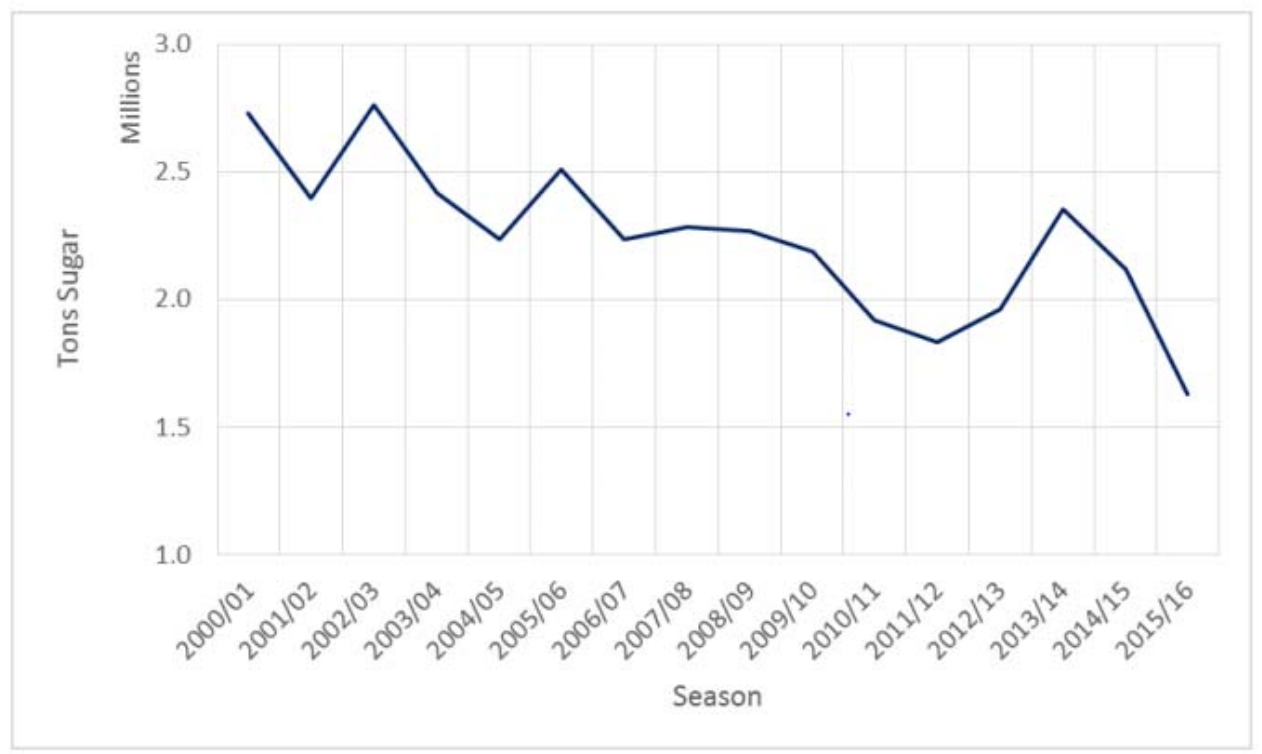

Fig. 1. Indicates the declining trend in the large-scale production of sugarcane production and particularly sucrose yields

Source: adopted from Harris (2016).

Following the declining trend in the large-scale production of sugar-cane and particularly sucrose yields (Fig. 1), this study considers the adoption of a material cost reduction accounting framework as an alternative to maintaining a competitive edge in the market share of sugarcane in the international market. The study's argument in support of Material Flow Cost Accounting (MFCA) is based upon the weaknesses associated with the conventional accounting principles in accounting for material wastage.

According to Schaltegger et al. (2010), MFCA is an EMA tool which can be used to reduce both environmental impact and cost, as well as improve organizations' business productivity by reducing waste and its associated cost. In addition, it measures the flow of raw materials in both physical and monetary units. The cost categories related to MFCA are material, energy, system, and waste management costs (Schmidt \& Nakajima, 2013).

Schmidt and Nakajima (2013) were one of the first accountants to find weaknesses in conventional cost accounting models, major among which is the fact that they do not provide sufficient required data. While conventional cost accounting (CCA) systems trace and interpret monetary value flows as product cost, thus focusing on the cost figures for each product in each process, MFCA focusses on mass balances in each process. In general, companies rather than focusing on the material losses generated from a process, focus on its the input materials and the quantity and/or quality of products they lead to. MFCA, on the other hand, takes into cognizance and measures input materials, output and non-product output (material losses), evaluating them in fiscal terms. It, therefore, performs better than traditional cost accounting models which provide insufficient information about the internal use of materials in manufacturing and resulting material losses, that are more suitable for appraising alternative processes and technologies which can lead to more efficient material and energy utilization (Sygulla et al., 2011). According to Sygulla et al. (2011), MFCA has been mainly implemented in practice in Japan, where it is seen as the new 'Kaizen' for many Japanese companies, and is promoted by the Japanese Ministry of Economy, Trade and Industry. It is also being implemented in Germany, though still at a low rate.

The hypothesis of this study is that Material Flow Cost Accounting (MFCA) is significantly sufficient to control cost and to maximize profitability in the sugar sucrose production.

The statement of problem. The continued decline in the sucrose quality of sugarcane and the general fall in the sugarcane profitability in the South African sugar industry is of great concern to policy makers. Not only does this ugly event poses a challenge to the major revenue generation to the South African economy, it threatens the existence of cane production in the continent of Africa, as South Africa is the leading producer of cane and possesses the most industrialized the sugarcane production system. Policy makers have, however, hypothesized that having an alternative to the cost reduction strategy on the material loses can salvage this critical situation. In the light of this, this paper sets out to develop an alternative MFCA measure as a 
best accounting practice which, if well appropriated, has a great chance of improving the quality and production of sugar cane in South Africa.The argument about the efficiency of resources particularly relating to waste reduction process is not only an issue of concern for environmentalists, scientists, activists, and environmental analyst and in an attempt to contribute to the issue relating to waste reduction from various direction, experts in the field of management accounting developed a tool for waste collection, MFCA to offer both non-financial and financial waste information to support wastereduction decisions by managers. It is believed that the adoption of this tool would be of immense benefit to sugarcane industry in South Africa.

The objectives of this paper focuses on MFCA. This paper categorizes MFCA as it identifies the importance of MFCA information for the optimization of production processes and material flow management tools. The objective is to present MFCA system outputs on example of sugar cane milling industry and indicates the relevance of acquisition of data from the MFCA system for the optimization of cane milling processes.

Historical background. In Japan, the MFCA method was first applied in 2000 and soon became widespread under the name Material Flow Cost Accounting. The first MFCA case studies, such as the one at the firm Nitto Denko, were funded by the Japanese Ministry of Trade and Industry (METI) which subsequently recommended further application of the idea. METI has since then continued to finance projects aimed at further developing the method and application context of MFCA, while numerous other independent studies have been published. Today, over 300 companies in Japan have experience with MFCA.

In the year 2007, Japan suggested that an MFCA norm be developed within the ISO 14000 family with the aim of setting out and standardizing general principles and frameworks for MFCA so as to support a more widespread adoption of the method and thus contribute to more efficient worldwide resource handling in companies. It was to involve the education of representatives or consultants of small and medium-sized companies about the MFCA and its inherent advantages - the simplicity of its basic concept and its scalability. It was however not to be developed into a certifiable process, as it generally only addresses proprietary and private in-company details and processes. Several countries such as Brazil, the United Kingdom, Finland, Malaysia, Mexico and South Africa, as well as Japan and Germany, were involved in drawing up the ISO norm which was adopted and published in 2011 as ISO 14051(Schmidt \& Nakajima, 2013).

\section{Theoretical framework}

As has been earlier pointed out, a high rate of the implementation of MFCA among Japanese companies has been observed, with the aim of reducing material losses rather than recycling wastes. They have found out that reducing material input and its resulting cost eventually leads to improved processing efficiency and reduced waste treatment costs, since it results in reduced waste. These two key activities in turn lead to a reduced environmental footprint of the manufacturing process.

Furthermore, the MFCA is not only a system providing data in physical and monetary units, but also shows the individual value of material flows. Material costs are a key component of material flow costs because they represent an important cost item in manufacturing companies. Material flows are reconstructed and analyzed within a quantity center to identify what part of input materials resulted in products, and which ones flowed out as material losses/waste. The MFCA also monitors the cost associated with all energy sources used within a quantity center, known as energy cost. Products and material losses are also allocated system costs, which are defined as all costs incurred when handling material flows within a company (e.g., personnel costs, etc.). Each material flow within a company (whether relating to products, raw materials, material losses, or works in progress) may be treated as a carrier of system. Output flows are always allocated system costs which are retransferred to subsequent flows and material stock. Waste disposal costs must also be allocated to material losses incurred by a quantity center.

\section{Empirical literature}

The MFCA was developed as an approach for improving resource efficiency in manufacturing companies by adopting the distribution of the various costs in the flows to products and residual materials. The trend development of MFCA has been further traced to its present day efficient application (Schmidt \& Nakajima, 2013). This paper argues that just as MFCA first achieved practical relevance and large-scale application in Japan, even to the point of being converted into an ISO standard, it can also be successfully applied within the South African context, particularly in the sugar can industry with remarkable results.

Hyršlová, Vágner, and Palásek (2011) present an application of the MFCA within the manufacturing plant of Lasselsberger, the largest manufacturer of ceramic tiles in the Czech Republic. Their study shows the importance of data acquired from the MFCA system, as well as its application to optimizing 
manufacturing processes under specific conditions for a company's manufacturing plant. Their findings confirm the uniqueness and advantage of the MFCA, in that it monitors materials' flow and the costs associated with product and material losses. The data acquired during this process enables management to identify and propose measures which can lead to more effective production and lower the volume of material losses. The advantages of the MFCA over traditional approaches can be classified into two:

- Economic: It's primary focus on material flows and all associated costs.

- Environmental: By focusing on the reduction waste through the reduction of unnecessary input, MFCA leads to a lower and better environmental by companies.

Doorasamy (2015) conducted a study which examined the role of MFCA in identifying waste (non-product output) and its effect on an organization's profitability. This was done by examining multiple case studies, which demonstrate MFCA as an important environmental management tool for ensuring the organizational sustainability. The studies also showed that there is inadequate information/education in many organizations about MFCA, and as such, they are not able to enjoy the benefits of adopting the MFCA. Since this concept is new to many industries, more structured guidelines relating to the adaptation of current management accounting practices to include environment-sensitive practices need to be set out and communicated to them. MFCA increases environmental costs transparency, allowing managers to identify saving opportunities which can be gained through adopting cleaner production (CP) techniques or technologies and make informed investment decisions.

Doorasamy and Garbharran (2015) investigated the efficiency of applying Material Flow Cost Accounting (MFCA) methods to identify cost of output from nonproduct materials. The study was conducted with the aim of providing support to managers during managerial strategic decision making process on issues affecting the process of cleaner production implementation. The study employed a paper producing company a case study located in KwaZuluNatal South Africa and from the information provided by the organization, we submit the evidence that Material Flow Cost Accounting (MFCA) technique is an important tool in identifying non-product values of output and costs. Hence the finding would enhance managerial skill in assessing the environmental and financial benefits of adopting cleaner production technologies and techniques. The company finally agreed that there is a growing gap between the company's efficiency and the adoption of this method and are therefore advised to integrate the current EMS system, which incorporates MFCA approach to ensure future profitability and sustainability

METI (2010) categorized Material Flow Cost Accounting (MFCA) as being a highly and rapidly appraised powerful approach through the adoption of simultaneously improved business efficiency, environmental impacts and consequently enhancing material losses transparency. MFCA is now recognized and consequently integrated as accounting tools needed in the environmental management system, whose contribution supports both the economies and environmental compatibility. The study addresses the MFCA as an efficient methodological approach to expose the monetary and quantitative impacts within the material flow management framework. It provides the basic foundation to ideas, identifies shortcomings from existing conventional methods and presents three enhancements for improvement: a procedure for a more detailed analysis, the explicit regard for lost of energy flows and forecast of system costs. He again argues that the adoption of MFCA could be extended to Data Envelopment Analysis (DEA), as it is one of the most frequently used analytical tool to appraise productive unitefficiency performance, based on inputs and outputs. This methods of analysis has been adopted for benchmarking and performance evaluation. Ultimately an organization employs this tool of analysis in her productive units and would want to optimally utilize all the resources in the production process, so that outputs are maximized from a given set of inputs.

The next section addresses various methodological approach through the implementation of models and MFCA principles in classifying production and waste cost.

\section{Methodological approach}

The foundation of these model frameworks are built upon the works of Fakoye (2014), Hyrslova, Vagner, and Palasek (2011)

The Figure 2 below indicates the fundamentals issues behind MFCA, in the conventional cost accounting, every costs could be apportioned to individual product and it is regarded as unit cost.

The material cost in the MFCA classification are appropriately divided between the residual or waste and the actual product, this however depends on ending points of the material used. Again, company system cost such as transport, processing and storage can be generated, which are again distributed between the wastes or the residuals and the main product based on the appropriate indicator's key. 


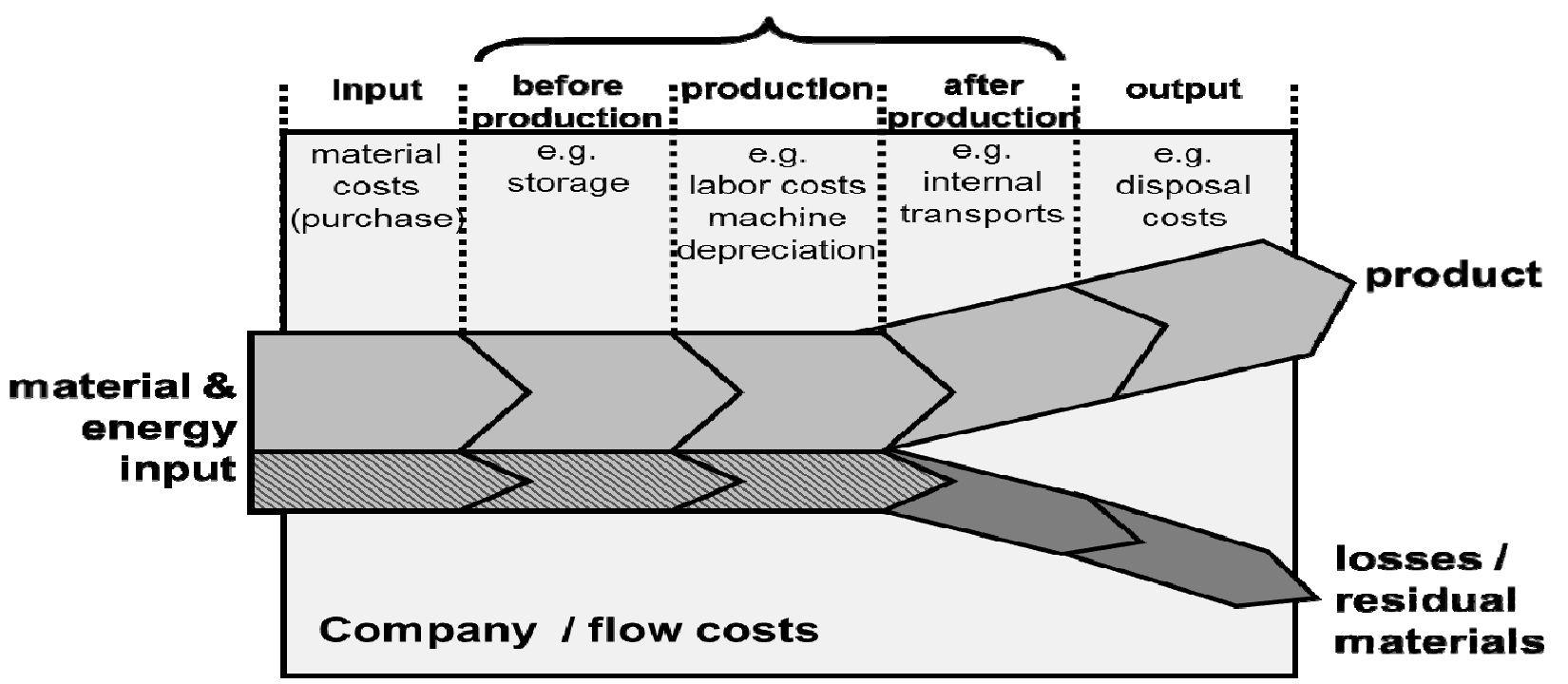

Fig. 2. Classification of production process

From Figure 3, through the asymmetry in the cost of material losses, provision for an improved measures can be improvized. From this method of analysis, possibility of cost reduction can lead to avoidance of material losses. Savings in terms of monetary value are higher in comparison to when production process of direct cost of residual or waste disposal are obtained. It, therefore, indicates, for instance, the chosen periods of amortization available for investment reduction in wastages are shorter and larger scope are open for environmental management or quality measurement.

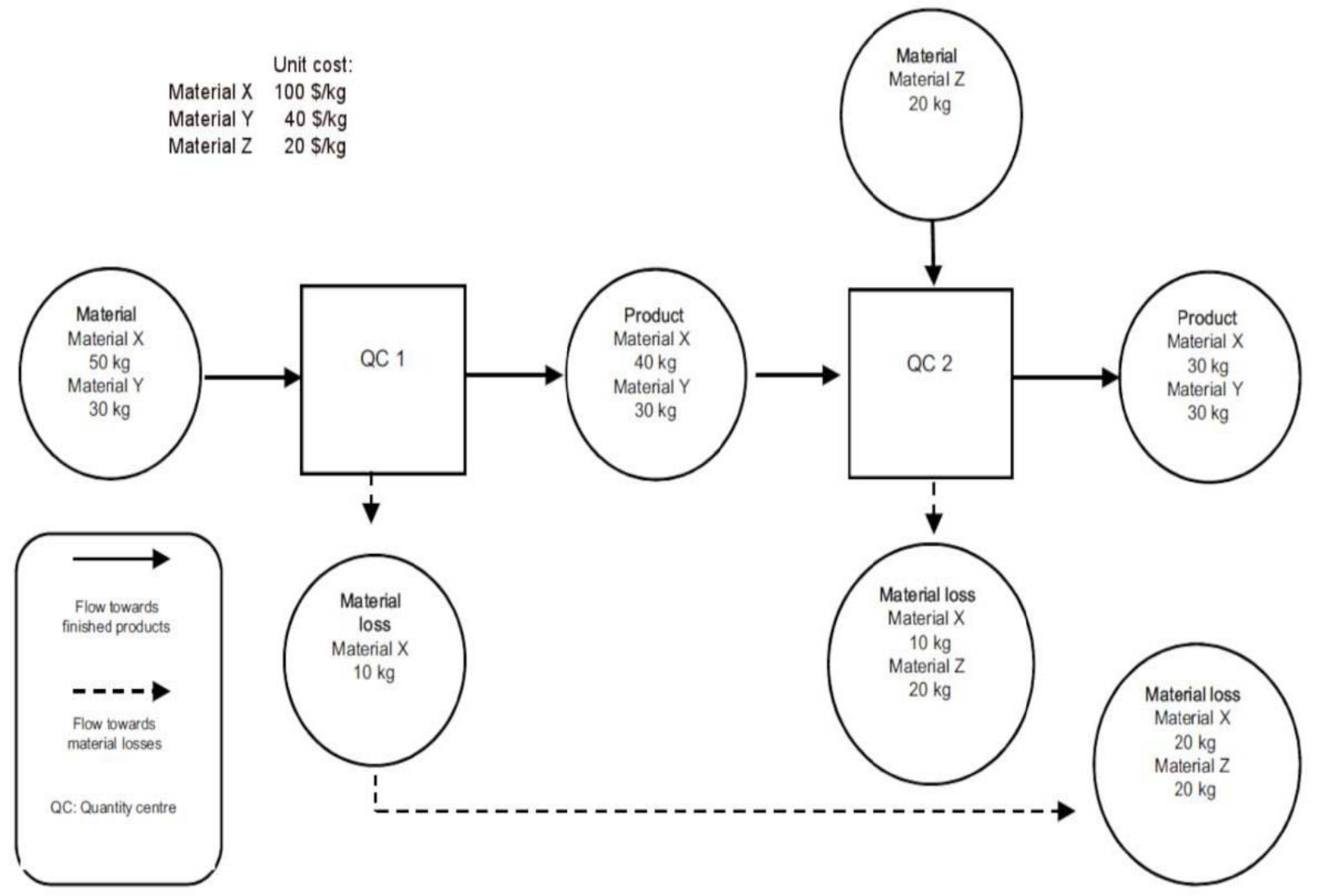

Fig. 3. A simple material flow

Source: adopted from Hyrslova, Vagner and Palasek (2011).

The material $\mathrm{X}, \mathrm{Y}$, and $\mathrm{Z}$ represents the possible cane varieties yielding various levels of sucrose in kilogram.
The direction of arrow indicates a flow directed towards both finished product and material losses. 
3.1. Decision making power of MFCA as a tool. It enables the miller and farmer to estimate losses from materials right from the harvesting period of the crop all through to the time manufacturing of sugar takes place at the milling station. The losses in material includesper day loss in sucrose (Harris, 2016). The organization experiences economic losses resulting material loss in terms of income and revenue to farmers due to the systemic RV indicating, that sugar cane quality through sucrose component is a factor that determine of quality, and consequently determine the farmers' return.The content of sucrose quantity in a given sugar determines the per ton quantity of cane required to be crushed in the sugar manufacturing firm. Hence, we can improve the efficiency of production by sourcing cane that is of high quality sucrose content. MFCA identify both in monetary and physical terms how important sucrose loss is to the milling industry. By adopting this methodology to detect losses of material, it enhances millers/ farmers diligence and therefore motivate them to control the 'time lag' of cut to crush by ensuring that sucrose content cane taken by farmer to the mill are of high quality. It again assists the management to possibly consider the value chain of the determining factors causing losses in sucrose among farmers and miller. It guides to determine the appropriate theoretical framework of MFCA and to adopt relevant model to either reject or accept the application of the MFCA theoretical framework.

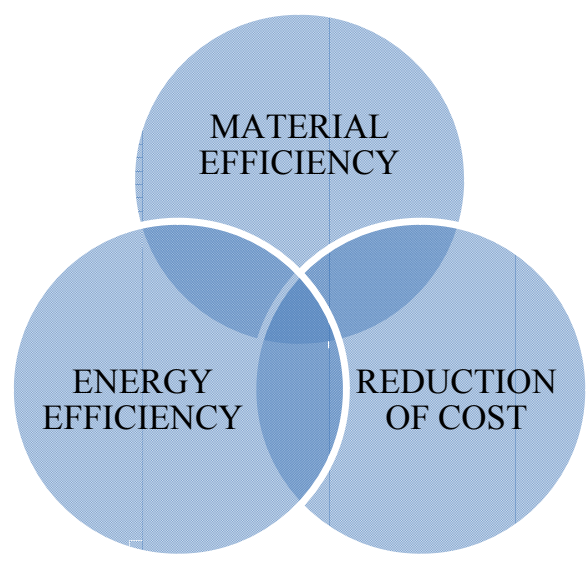

Fig. 4. The role of MFCA in an organization

Source: adopted from Fakoya (2014).

From Figure 4, the role of MFCA on information transmission is the focus of this section. For internal decision-making process to be efficiently managed in the organization, the appropriate skills in managing material and energy efficiency that brings about an observable reduction in residual cost is required. The accounts are therefore expected to apportion costs to various stages of production process, this process is otherwise called MFCA framework as indicated in Figure 5.
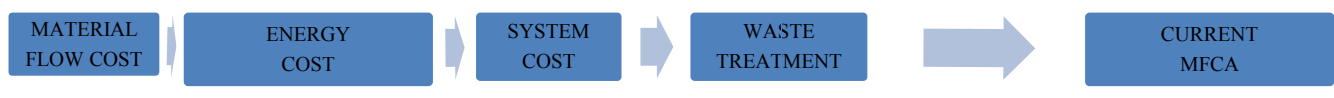

Fig. 5. Existing MFCA Framework

Source: augmented from Fakoya (2014).

For the purpose of simplicity, MFCA groups various costs into material costs, energy costs,systems costs and waste treatment costs (METI, 2007). This is further specified according to METI (2007) as:

- Cost of material which includes costs on input materials, and auxiliary materials costs such assolvents, detergents and catalysts;
Systems cost such as cost of labor, overhead costs and other deprecation charges.

- Energy costs include electricity cost, utility bill, fuel and other related energy costs.

- Treatment costs on waste are the incurred costs in the process of conversion of waste to an acceptable international accounting standard before it is allowed to flow the environment. 
Table 1. Hypothetical expression of MFCA approach

\begin{tabular}{|l|c|c|c|}
\hline \multicolumn{1}{|c|}{ Material cost } & $\begin{array}{c}\text { Environmental } \\
\text { cost accounting }\end{array}$ & $\begin{array}{c}\text { Cost on } \\
\text { wastage }\end{array}$ & $\begin{array}{c}\text { Material flow cost } \\
\text { accounting }\end{array}$ \\
\hline $\begin{array}{l}\text { Cost of material } \\
\text { during production, } \\
\text { e.g., packaging }\end{array}$ & & $\mathrm{XXX}$ & $\mathrm{XXX}$ \\
\hline $\begin{array}{l}\text { Cost of material } \\
\text { during wastages }\end{array}$ & & $\mathrm{XXX}$ & $\mathrm{XXX}$ \\
\hline System cost & & $\mathrm{XXX}$ & $\mathrm{XXX}$ \\
\hline $\begin{array}{l}\text { Material losses } \\
\text { incurred before } \\
\text { system cost }\end{array}$ & & $\mathrm{XXX}$ & $\mathrm{XXX}$ \\
\hline $\begin{array}{l}\text { Material losses } \\
\text { incurred after } \\
\text { system cost }\end{array}$ & $\mathrm{XXX}$ & & \\
\hline $\begin{array}{l}\text { Cost incurred on } \\
\text { waste }\end{array}$ & & & \\
\hline
\end{tabular}

Source: author's computation.
Table 1 differentiated the environmental accounting (whose attention is limited to final cost of input) from material cost accounting (that gives attention to process cost) and attempt to establish that the theory that MFCA gives attention to more details than the conventional cost accounting. It also revealed the unclassified cost capable of increasing production cost and hampering the firm's value.

From Table 2 above, the cost of material losses has been completely identified for the two production periods. In the study's example, the losses are R1015.45 for production period one and 1202.54 for production period two. The losses were pro-rated from the system, material and energy costs of the company. If material losses are apportioned appropriately, these costs would be saved for the organizational profitability.

Table 2. Cost report from south milling industry for the year 2015-2016 and 2016-2017 respectively

\begin{tabular}{|c|c|c|c|c|c|c|c|c|c|c|}
\hline & \multicolumn{5}{|c|}{$\mathrm{CR}_{1}$} & \multicolumn{5}{|c|}{$\mathrm{CR}_{2}$} \\
\hline & $\begin{array}{l}\text { Material } \\
\text { cost }\end{array}$ & $\begin{array}{l}\text { Energy } \\
\text { cost }\end{array}$ & $\begin{array}{l}\text { System } \\
\text { cost }\end{array}$ & $\begin{array}{l}\text { Waste mgt } \\
\text { cost }\end{array}$ & Total & $\begin{array}{c}\text { Material } \\
\text { cost }\end{array}$ & Energy cost & System cost & $\begin{array}{l}\text { Waste mgt } \\
\text { cost }\end{array}$ & Total \\
\hline $\begin{array}{l}\text { Manpower cost } \\
\text { in } \mathrm{CR}\end{array}$ & 10279 & 12,751 & 44,917 & 679 & 68,626 & 10,694 & 13,657 & 49,094 & 734.45 & $74,179.45$ \\
\hline $\begin{array}{l}\text { Process cost in } \\
\mathrm{CR}\end{array}$ & 553 & 391 & 67 & 10.11 & 1021.1 & 682 & 484 & 148 & 131.4 & 1445.4 \\
\hline $\begin{array}{l}\text { Season } \\
\text { maintenance }\end{array}$ & 640 & 2048 & 5686 & 83.74 & 8457.74 & 735 & 1,632 & 6657 & 90.24 & 9114.24 \\
\hline $\begin{array}{l}\text { Off-crop } \\
\text { maintenace }\end{array}$ & 430 & 6754 & 18468 & 184.86 & 25836.86 & 506 & 5129 & 14,890 & 205.25 & $20,730.25$ \\
\hline Other expences & 106 & 308 & 5360 & 57.74 & 5831.74 & 110 & 281 & 3729 & 41.20 & 41.20 \\
\hline Products & \multicolumn{5}{|c|}{$\mathrm{XXX}$} & \multicolumn{3}{|c|}{408,987 tons } & & 408,987 \\
\hline Material losses & & & & 1015.45 & & & & & 1202.54 & 1202.54 \\
\hline
\end{tabular}

Source: authors' computation (2017).

However, in the real life practice, only the R1015.45 and 1202.54 are perceived as waste disposal costs emanating from cost of material losses. At any rate, if the company has the full knowledge of the complete costs differently separated from material waste coming from technical efficiency measures, the order of reduction in the material losses would improve company's worth. This analysis is the advantage of MFCA. A further step is to establish the procedure or analysis of possible residual or waste cost.

3.2. Procedure and analysis: Given that $x$ and $y$ are the inputs of material involved in the production process to produce finished good of sucrose in the South African sugarcane (SC) processing as proxy by $\mathrm{c}$ and $\mathrm{d}$, given that balances in mass resulting from the differences is $\varepsilon$, then from the MFCA perspectives, waste created in process $X$ is could mathematically derived such that:

$(\varepsilon)=(x+y)-(c-d)$
Accordingly, then streams of waste from the South African sugar industry could be in the value (per MFCA) as:

$E($ in $R)=\varepsilon(Q) *[(x(Q) * R x+y(Q) * R y+C C] /$

/ $[x(Q)+y(Q)]$,

where

$E$ denotes streams of waste of such as baggages;

(Q) implies the equivalent physical quantities of sucrose and other useful quantities from the sugar cane;

$R$ rates per physical unit;

$C C($ cost of conversion $)=\sum R Q i * R i$.

This cost includes the four classification of cost according to model in Figure 5.

Where $R Q_{i}=$ quantity of $i^{\text {th }}$ resource. 
What makes MFCA unique is not the summation process, but the procedure of process iterative involving the scaling up of costs in each of the process as well as proportionately loading the value on the outputs, hence model (2) could aid the control of incoming inputs of material systematically to finished product such that waste cost is separated from overall product.

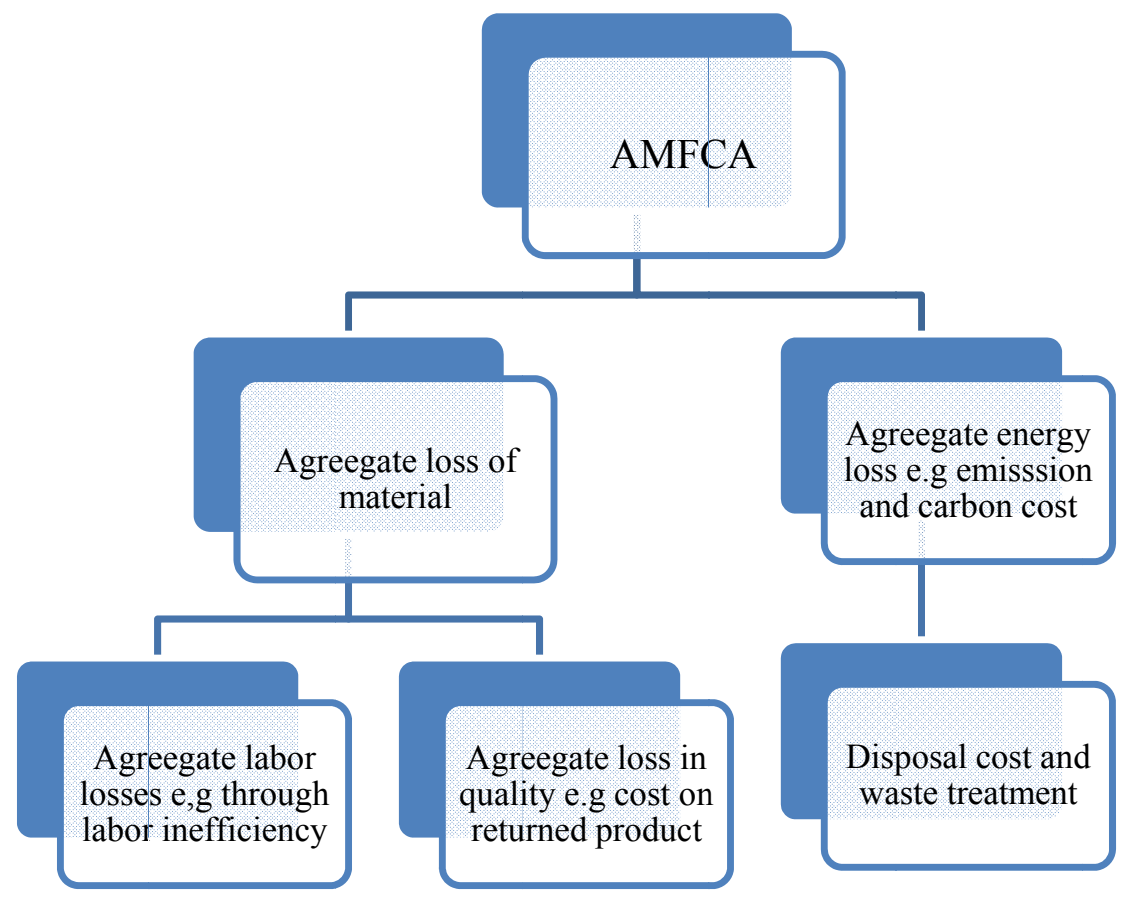

Fig. 6. Adjusted MFCA framework for improved process waste reduction decisions

Source: augmented from Fakoya (2014).

Figure 6 above indicates the MFCA adjustment process to establish the current MFCA quantitative analysis for an improved waste reduction process and decisions making paradigm for cane milling industry.
The Figure 6 above depicts an augmented MFCA procedure from the direction of total material and energy losses. This further breaks down to absorb total labor losses, cost of returns in production and the treatment in waste disposal.

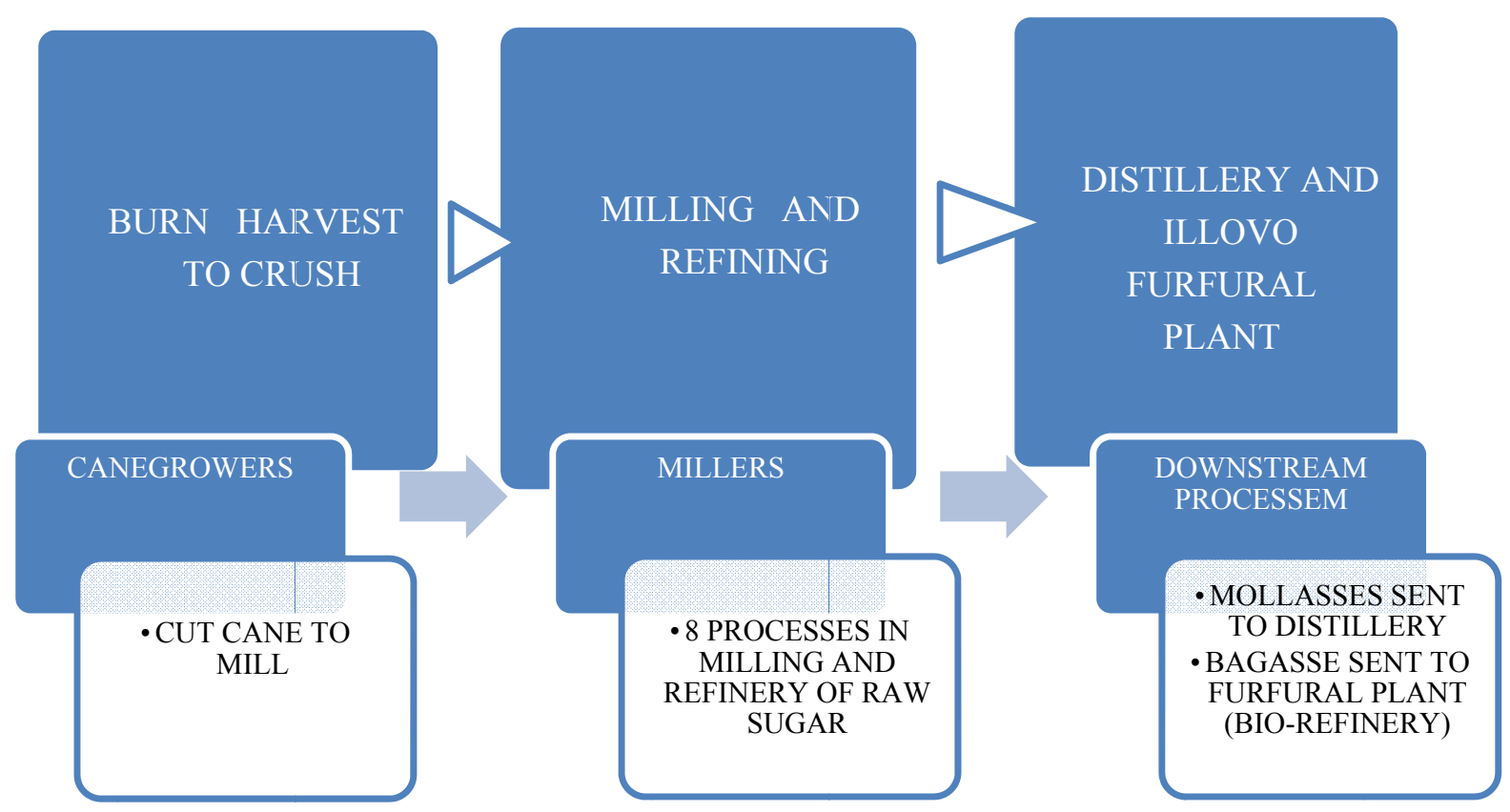

Fig. 7. Process flow diagram of sugar industry

Source: augmented from Fakoya (2014), MFCA. 
MFCA adoption is given to trace material flows throughout the production processes as indicated in Figure 7, it provides a comprehensive overview of performance of South African sugar industry. The model summarizes the sugar production process from the farmers to the final milling process at the industry. Waste in the production process need to be acknowledged and accounted for. Waste from various stages are itemized as follows:

Cane grower stage: The farmer wastage cost may include payment for idle time, excess fertilizers used, excess manpower charges, delay in the harvesting periods, etc.

Milling and refining of raw materials: Wastes in the production process includes the mediation between labor versus capital intensity, harvest to crush delay, packaging and branding, poor transportation network, etc.

\section{Conclusion and recommendation}

Effectiveness of MFCA as a tool to improving sucrose quality in sugarcane production has been established. The study has been able to identify the major limitations inherent in the conventional accounting methods. The study hypothesis that can MFCA as tool increase organizational profitability has also been verified. However, the study is constraint with the limitation of data to adequately classified production cost appropriately for the South African sugarcane industry. This data limitation is partly caused by the low level of MFCA acknowledgement and its adoption among the sugarcane industry in South Africa. The study has contributed to extant world-wide literature in some sense: the study has been able to adopt and apply data from South African data base to develop MFCA accounting principles which before now has not been done in literature. Again, the study has been able to adopt MFCA models to classify cost of finished products from residual cost. The implications of this study to policy application rest solely on need for maximization of profitability in industries resulting from adequate waste reduction management skills. The MFCA skill has not been integrated into the curriculum in the South African schools, however, it is expedient that special considerations be devoted to the development of this area of accounting system.

\section{References}

1. South African Sugar Association (2016). Annual and Monthly Repor. October. Durban.

2. Bennett, M., Schaltegger, S., \& Zvezdov, D. (2013). Exploring Corporate Practices in Management Accounting for Sustainability, 1-56. Retrieved from http://www.icaew.com/academic

3. Fakoya, M. B. (2014). An adjusted material flow cost accounting framework for process waste-reduction decisions in the South African Brewery Industry (PhD thesis at the University of Pretoria).

4. Harris, A. (2016). Determining the cost of post-harvest deterioration in a South African sugarcane supply chain (M.Sc. thesis at the Cranfield University).

5. Hyršlová, J., Vágner, M., Palásek, J. (2011). Material Flow Cost Accounting (MFCA) - tool for the optimization of corporate production processes. Business, Management and Education, 9(1), 5-18. http://dx.doi.org/10.3846/bme.2011.01

6. Jasch, C. (2009). Environmental and Material Flow Cost Accounting Principles and Procedures. Journal of Industrial Ecology. Springer science and Business Media: Berlin, 25(2), 832-834.

7. METI - Ministry of Economy, Trade and Industry (2007). Guide for Material Flow Cost Accounting. Japan: Environmental Industries Office: Environmental Policy Division.

8. Ministry of Economy, Trade and Industry (2010). Environmental Management Accounting Workbook. Tokyo, Ministry of Economy, Trade and Industry Japan.

9. Schmidt, M., \& Nakajima, M. (2013). Material Flow Cost Accounting as an Approach to Improve Resource Efficiency in Manufacturing Companies. Resources, 2(3), 358-369. http://dx.doi.org/10.3390/resources2030358

10. Stainbank, G. (2011). Value Migration in the South African Sugar Industry. University of Cape Town.

11. Sygulla, R., Bierer, A., \& Gotze, U. (2011). Material Flow Cost Accounting - Proposals for Improving the Evaluation of Monetary Effects of Resource Savings Process Designs. 44th Conference on Manufacturing Systems. Wisconsin, USA. Retrieved from https://tu-chemnitz.de/wirtschaft/bwl3/DownloadAllgemeinOffen/44thCIRP_MFCA.pdf 